by attracting and binding proteins that enhance its expression.

PLoS Biol. 9, e1001046 (2011)

\section{ORGANIC CHEMISTRY}

\section{Fusing rings with fluorine}

The Friedel-Crafts reaction is one of the most beloved and well used in the organic chemist's recipe book, allowing the attachment of chemical groups to aromatic rings through a carbon-carbon bond. Jay Siegel and his colleagues at the University of Zurich in Switzerland have now devised a way to attach one aromatic ring to another, which they say will allow the synthesis of more complex compounds.

Using a silicon-based reagent and an acid catalyst, the authors activated the normally stable bond between a fluorine atom and one of the carbon atoms of an aromatic ring. This led, in turn, to the formation of a new bond between the carbon and another carbon atom on a different aromatic ring. Meanwhile, the acid catalyst is regenerated to drive another cycle of the reaction.

Science 332, 574-577 (2011)

\section{NEUROSCIENCE}

\section{Monkey recalls what monkey saw}

Humans can remember information from the past, such as the appearance of a childhood home, but attempts to test this ability in other animals have been hampered by a lack of good testing methods. Now Benjamin Basile and Robert Hampton of Emory University in Atlanta, Georgia, have designed a touchscreen computer task for rhesus macaques and used it to show that the primates can recall simple shapes from memory.

Five male monkeys trained on the computer task were able to fill in blanks on a grid to reproduce previously viewed two- and three-square shapes, demonstrating recall. The finding may provide a new animal model for memory studies and suggests that a common ancestor with humans came under selection pressure for this detailed and flexible use of memory.

Curr. Biol. doi:10.1016/j. cub.2011.03.044 (2011)

\section{IMMUNOLOGY \\ Worm-proofing the gut}

Pathogenic worms have more than the immune system to contend with in mammals, with a mucus-forming protein also mounting a defence. Sugar-coated mucin proteins form a thick protective mucus layer over organs such as the gut and lungs. David Thornton and Richard Grencis at the University of Manchester, UK, and their team report that the mucin MUC5AC also directly lowers the viability of a gutdwelling nematode worm.

MUC5AC normally occurs in the lungs, but intestinal levels shoot up in mice infected with Trichuris muris worms, a close relative of a nematode that afflicts humans. Mice lacking the Muc5ac gene had chronic worm infections, despite showing strong immune responses. In T. muris cultured with human cells, the protein limited the worms' production of the cellular energy molecule ATP — a sign of viability.

J. Exp. Med. doi:10.1084/ jem.20102057 (2011)

\section{OCEANOGRAPHY}

\section{A tsunami's trip around the world}

Rather than travelling straight across the Pacific Ocean, the Sumatran tsunami of December 2004 (pictured) took a roundabout route. It headed southwards towards Antarctica before looping back up to arrive at the northwest coast of North America. The 22,000-kilometre-long trip followed mid-oceanic ridges.

Alexander Rabinovich of the Canadian Department of Fisheries and Oceans in Sidney, British Columbia, and his

COMMUNITY CHOICE

The most viewed papers in science

\title{
EVOLUTIONARY GENETICS
}

\section{Hunting for birth-timing genes}

\section{- highly READ \\ on plos.org \\ in April}

other primates.

Louis Muglia at Vanderbilt University in Nashville, Tennessee, and his colleagues compared gestation times relative to neonatal size across 20 primate species and found that humans have the shortest gestation time - probably to make the delivery of large-headed babies through narrow birth canals easier. For this to happen, the researchers reasoned that genes regulating birth timing have probably evolved faster in humans. So they looked for genes showing signs of accelerated evolution along the human lineage.

The authors selected 150 genes and analysed their surrounding regions in the genomes of 328 mothers, teasing out one gene, FSHR, with the strongest link to preterm birth. PLoS Genet. 7, e1001365 (2011)

co-workers analysed data from pressure sensors deep in the northeast Pacific Ocean. The team detected tsunami waves at the first sensors around 34-35 hours after the earthquake and inferred the waves' direction by analysing their time of arrival at different sensors.

The waves continued for 3.5 days, suggesting that tsunamis produce a long-lasting energy flux that is conserved and transmitted by oceanic ridges. Geophys. Res. Lett. doi:10.1029/ 2011GL047026 (2011)

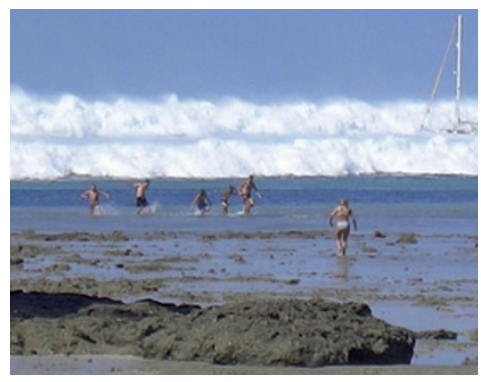

METABOLISM

\section{Diabetes drug affects the brain}

The diabetes drug rosiglitazone improves insulin sensitivity by acting not only on fat and muscle cells, but also on the brain.
Rosiglitazone binds to a protein receptor called PPAR- $\gamma$, which regulates lipid and glucose metabolism. One side effect, however, is weight gain. Randy Seeley and his colleagues at the University of Cincinnati in Ohio found that the drug activates PPAR- $\gamma$ in the rat central nervous system. Administering rosiglitazone directly to the brain, or overexpressing PPAR- $\gamma$ in a brain region called the hypothalamus, boosted the rats' appetite and weight gain.

Meanwhile, Jerrold Olefsky at the University of California, San Diego, Michael Schwartz at the University of Washington in Seattle and their colleagues found that mice lacking PPAR- $\gamma$ in neurons ate less food and used more energy than normal mice. But rosiglitazone didn't work in these mice - it seems that active neuronal PPAR- $\gamma$ is required for the drug's insulinsensitizing effects.

Nature Med. doi:10.1038/ nm.2349; doi:10.1038/nm.2332 (2011)

\section{$\rightarrow$ NATURE.COM}

For the latest research published by Naturevisit:

www.nature.com/latestresearch 